University of Nebraska - Lincoln

DigitalCommons@University of Nebraska - Lincoln

\title{
Interstitial-nitrogen effect on phase transition and magnetocaloric effect in $\mathrm{Mn}(\mathrm{As}, \mathrm{Si})$ (invited)
}

W. B. Cui

Shenyang National Laboratory for Materials Science, Institute of Metal Research and International Center for Materials Physics, Chinese Academy of Sciences

X. K. LV

Shenyang National Laboratory for Materials Science, Institute of Metal Research and International Center for Materials Physics, Chinese Academy of Sciences

F. Yang Shenyang National Laboratory for Materials Science, Institute of Metal Research and International Center for Materials Physics, Chinese Academy of Sciences

Ralph Skomski

University of Nebraska-Lincoln, rskomski2@unl.edu

Y. Yu

University of Nebraska-Lincoln

See next page for additional authors

Follow this and additional works at: https://digitalcommons.unl.edu/physicsskomski

Part of the Physics Commons

Cui, W. B.; Lv, X. K.; Yang, F.; Skomski, Ralph; Yu, Y.; Zhao, X. G.; Liu, W.; and Zhang, Z.D., "Interstitialnitrogen effect on phase transition and magnetocaloric effect in $\mathrm{Mn}(\mathrm{As}, \mathrm{Si})$ (invited)" (2010). Ralph Skomski Publications. 67.

https://digitalcommons.unl.edu/physicsskomski/67

This Article is brought to you for free and open access by the Research Papers in Physics and Astronomy at DigitalCommons@University of Nebraska - Lincoln. It has been accepted for inclusion in Ralph Skomski Publications by an authorized administrator of DigitalCommons@University of Nebraska - Lincoln. 


\section{Authors}

W. B. Cui, X. K. Lv, F. Yang, Ralph Skomski, Y. Yu, X. G. Zhao, W. Liu, and Z.D. Zhang 


\title{
Interstitial-nitrogen effect on phase transition and magnetocaloric effect in $\operatorname{Mn}($ As,Si) (invited)
}

\author{
W. B. Cui, ${ }^{1}$ X. K. Lv, ${ }^{1}$ F. Yang, ${ }^{1}{ }^{\text {Y. }}$ Yu, ${ }^{2}$ R. Skomski, ${ }^{2}$ X. G. Zhao, ${ }^{1}$ W. Liu, ${ }^{1,2, a)}$ and \\ Z. D. Zhang ${ }^{1}$ \\ ${ }^{1}$ Shenyang National Laboratory for Materials Science, Institute of Metal Research and International Center \\ for Materials Physics, Chinese Academy of Sciences, Shenyang 110016, People's Republic of China \\ ${ }^{2}$ Department of Physics and Astronomy and Nebraska Center for Materials and Nanoscience, University of \\ Nebraska, Lincoln, Nebraska 68588-0113 USA
}

(Presented 19 January 2010; received 2 November 2009; accepted 2 December 2009; published online 3 May 2010)

The effect of interstitial nitrogen on the phase transition and magnetocaloric behavior of $\mathrm{MnAs}_{1-\mathrm{x}} \mathrm{Si}_{\mathrm{x}} \mathrm{N}_{\delta}(\mathrm{x}=0.03,0.06$, and 0.09) is investigated. The interstitial nitrogen atoms cause the step-scanned $\mathrm{x}$-ray diffraction peaks to shift toward lower angles and lower the Curie temperature, whereas silicon addition increases the Curie temperature to near room temperature. The thermal hysteresis is reduced to nearly 0 in $\mathrm{MnAs}_{1-\mathrm{x}} \mathrm{Si}_{\mathrm{x}} \mathrm{N}_{\delta}$, which is beneficial to practical applications. For a field change of $5 \mathrm{~T}$, the largest magnetic entropy change and refrigerant capacity are 14.6 $\mathrm{J} \mathrm{kg}^{-1} \mathrm{~K}^{-1}$ at $247 \mathrm{~K}$ and $360 \mathrm{~J} \mathrm{~kg}^{-1}$, which is slightly higher than the entropy change in the parent alloy. Finally, we briefly discuss the occurrence and origin of the "virgin effect" in MnAs. (C) 2010 American Institute of Physics. [doi:10.1063/1.3358617]

\section{INTRODUCTION}

The magnetocaloric effect (MCE) means the isothermal entropy changes in a magnetic field and adiabatically changes the temperature. Magnetic refrigeration is a technology with the potential to partially replace commonly used gas-compression/expansion technology which suffers from low efficiency and from environmental concerns. In order to realize this aim, it is important to explore compounds with large entropy change $\Delta S_{\max }$ near room temperature. Compounds with Curie temperatures $T_{c}$ around room temperature have therefore attracted particular interest. A suitable starting material is MnAs, characterized by $T_{c}=318 \mathrm{~K}$ and $\Delta S_{\max }$ $\approx 40 \mathrm{~J} \mathrm{~kg}^{-1} \mathrm{~K}^{-1}$ under a field change of $5 \mathrm{~T}$, and by a firstorder transition from a hexagonal phase with ferromagnetic order to an orthorhombic phase with paramagnetic spin structure. ${ }^{1}$

One way to tune the Curie temperature and thermal hysteresis of MnAs is to use atomic substitutions. However, the MnAs system exhibits a pronounced sensitivity to the lattice pressure $^{2}$ and applied field, ${ }^{3}$ so that the atomic substitutions ${ }^{4,5}$ tend to yield, leads to the large thermal and magnetic hysteresis. Here we explore a different approach, namely, the use of interstitial atoms to control the Curie temperature and MCE of MnAs. There are the reports of the interstitial effects of hydrogen ${ }^{6}$ and carbon $^{7}$ in $\mathrm{La}(\mathrm{Fe}, \mathrm{Si})_{13}$ alloys. Our focus is on nitrogen interstitial with the primary aim of reducing hysteresis losses, and with the secondary aim of controlling the ordering temperature and the entropy in $\mathrm{Mn}(\mathrm{As}, \mathrm{Si})$ alloys. Little work has been done on the magnetocaloric properties of interstitially modified MnAs, mostly on nitrogen in MnAs has not been considered in the literature so far.

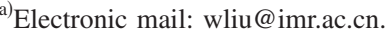

\section{SCIENTIFIC BACKGROUND}

The MCE is caused by the entropy change $\Delta S$ of a magnetic material in an external magnetic field $B=\mu_{0} H$. High and low magnetic fields correspond to high and low degrees of magnetic order, respectively, and therefore to low and high entropies. Under adiabatic conditions, $\Delta S$ must be compensated by the lattice entropy change which leads to the temperature change of the working medium. Quantitatively, the entropy is determined from the thermodynamic Maxwell relation

$$
\left(\frac{\partial S}{\partial B}\right)_{T}=\left(\frac{\partial M}{\partial T}\right)_{B}
$$

For magnetization measurement made at temperature interval, $\Delta S$ can be calculated by means of changing the Eq. (1) into the following form:

$$
\Delta S(T, \Delta B)=\int_{0}^{B}\left(\frac{\partial M}{\partial T}\right) d B
$$

In order to transfer the continuous accumulation into discrete integration, Eq. (2a) can be written into the following form:

$$
\Delta S(T, \Delta B)=\sum_{i} \frac{M_{i}\left(T_{i}^{\prime}, B_{i}\right)-M_{i}\left(T_{i}, B_{i}\right)}{T_{i}^{\prime}-T_{i}} \Delta B,
$$

where $M_{i}\left(T_{i}^{\prime}, B_{i}\right)$ and $M_{i}\left(T_{i}, B_{i}\right)$ represent the value of magnetization at the temperature $T_{i}^{\prime}$ and $T_{i}$ at a magnetic field $B_{i}$. $T$ is the average temperature of $T_{i}^{\prime}$ and $T_{i}$. The $\Delta B$ is the step of field increase. Equation (2b) shows that the magnetic entropy change is numerically equal to the integration area enclosed by isothermal magnetization curves at the initial working temperature and working final temperature. On the other hand, according to the second law of thermodynamics $(\partial S / \partial T)_{B, p}=\left[C_{p}(T, B)\right] / T$. Integration of this equation yields 


$$
\Delta S(T, B)=\int_{0}^{T} \frac{C\left(T^{\prime}, B\right)-C\left(T^{\prime}, 0\right)}{T^{\prime}} d T^{\prime},
$$

where $C\left(T^{\prime}, B\right)$ and $C(T, 0)$ are the values of the heat capacity measured in a field $B$ and in 0 field, respectively.

Generally, for a second-order phase transition, either of the two methods mentioned above can be used. However, for a first-order phase transition, especially in a phase transition where magnetic transition is strongly correlated with structural transition, the values calculated by the two methods are different. The validity of Eq. (2) for calculating the magnetic entropy change it subject to controversy, ${ }^{8,9}$ and it is usually assumed that Eq. (3) yields a more accurate $\Delta S$ than Eq. (2). The reason is the coexistence of ferromagnetic and paramagnetic states with structural hysteresis and only approximately known volume fractions. However, the specific heat is often difficult to determine, so some efforts have be made to improve the calculation method based on Eq. (2). ${ }^{10}$ In the present paper, the magnetic entropy change is calculated from Eq. (2) because the hysteresis is reduced to nearly 0 and the metamagnetism in $\mathrm{MnAs}_{1-\mathrm{x}} \mathrm{Si}_{\mathrm{x}} \mathrm{N}_{\delta}$ is virtually absent.

Another quantity used to evaluate the magnetocaloric properties is the refrigerant capacity (RC) which means the max heat can be extract in a refrigeration process. Generally, there are two ways to determine RC. One is to numerically integrate the area under $\Delta S$ in the $\Delta S(T)$ curve, using the temperature at half-maximum of the $\Delta S$ peak value as the integration limit. ${ }^{11}$ The second one is the method proposed by Wood and Porter. ${ }^{12}$ Wood and Potter defined there RC for a reversible refrigeration cycle operating between the temperature of the hot reservoir and the temperature of the cold reservoir as $\mathrm{RC}=\Delta S_{m} \Delta T$, where $\Delta S_{m}$ is the magnetic entropy change at the hot and cold ends of the cycle and $\Delta T=T_{h}$ $-T_{c}$. According to this approach, for a given magnetic refrigerant the optimum refrigeration cycle occurs when the quantity $\Delta S_{m} \Delta T$ is max. In the present paper, the RC values are calculated by the first method.

\section{EXPERIMENTAL METHODS}

The $\mathrm{MnAs}_{1-\mathrm{x}} \mathrm{Si}_{\mathrm{x}} \mathrm{N}_{\delta}$ compounds ( $\mathrm{x}=0.03,0.06$, and 0.09) are prepared by mechanical alloying $\mathrm{Mn}$, As, and $\mathrm{Si}_{3} \mathrm{~N}_{4}$ mixed powders with purity higher than $99.9 \%$, in order to avoid the volatilization of As and time-exhausting solid-state reaction. The interstitial nitrogen atoms are introduced by $\mathrm{Si}_{3} \mathrm{~N}_{4}$. Mixtures of $10 \mathrm{~g}$ were sealed in hardened stainless steel vials with stainless steel balls of $12 \mathrm{~mm}$ diameter in a glove box filled with high purity argon. The mechanically alloyed powders were annealed at $773 \mathrm{~K}$ for $2 \mathrm{~h}$ and then annealed at $923 \mathrm{~K}$ for $2 \mathrm{~h}$ in vacuum better than $10^{-3} \mathrm{~Pa}$. $\mathrm{X}$-ray diffraction (XRD) analysis was conducted using $\mathrm{Cu} \mathrm{K} \alpha$ radiation with a Rigaku D/Max- $\gamma \mathrm{A}$ diffractometer equipped with a graphite crystal monochromator. The magnetic properties were measured using a superconducting quantum interference device with fields up to $5 \mathrm{~T}$.

\section{RESULTS AND DISCUSSION}

The XRD patterns shown in Fig. 1(a) indicate that the $\mathrm{MnAs}_{1-\mathrm{x}} \mathrm{Si}_{\mathrm{x}} \mathrm{N}_{\delta}(\mathrm{x}=0.03,0.06$, and 0.09$)$ alloys crystallize in
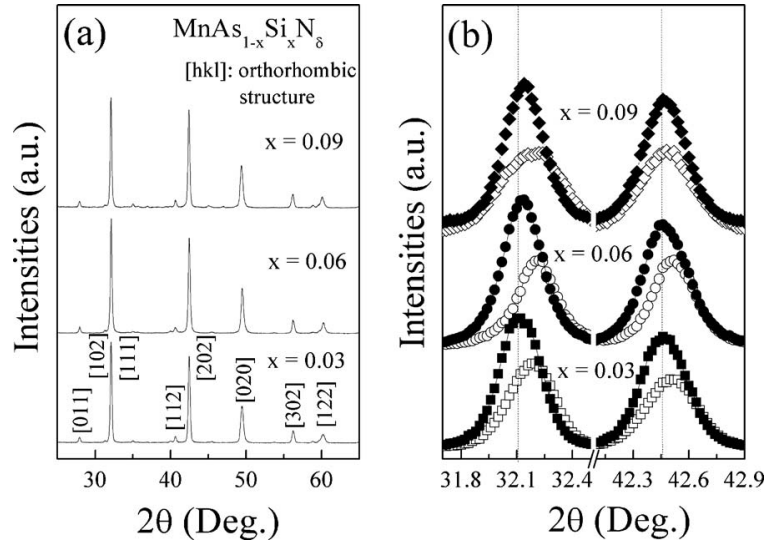

FIG. 1. Structure of $\mathrm{MnAs}_{1-\mathrm{x}} \mathrm{Si}_{\mathrm{x}} \mathrm{N}_{\delta}$ : (a) XRD patterns of $\mathrm{MnAs}_{1-\mathrm{x}} \mathrm{Si}_{\mathrm{X}} \mathrm{N}_{\delta}$ $(\mathrm{x}=0.03,0.06$, and 0.09$)$ and (b) step-scanned XRD patterns from $31.7^{\circ}$ to $32.5^{\circ}$ and from $42.1^{\circ}$ to $42.7^{\circ}$ at room temperature for $\mathrm{MnAs}_{1-\mathrm{x}} \mathrm{Si}_{\mathrm{x}}$ (white symbols) and $\mathrm{MnAs}_{1-\mathrm{x}} \mathrm{Si}_{\mathrm{x}} \mathrm{N}_{\delta}(\mathrm{x}=0.03,0.06$, and 0.09 , black symbols).

orthorhombic MnP-type structure. It is known that the alloys with MnP-type structure are paramagnetic which means that the Curie temperature of these nitrides is below room temperature. Increasing the $\mathrm{Si}$ content leads to a change from a paramagnetic state with $\mathrm{MnP}$-type structure in $\mathrm{MnAs}_{0.97} \mathrm{Si}_{0.03}$ and $\mathrm{MnAs}_{0.94} \mathrm{Si}_{0.06}$ to a ferromagnetic state with NiAs-type structure in $\mathrm{MnAs}_{0.91} \mathrm{Si}_{0.09}$ at room temperature. ${ }^{13}$ Fig. 1(b) compares the step-scanned XRD patterns of $\mathrm{MnAs}_{1-\mathrm{x}} \mathrm{Si}_{\mathrm{X}} \mathrm{N}_{\delta}$ $(\mathrm{x}=0.03,0.06$, and 0.09$)$ alloys with those of their parent alloys. Compared to the parent alloys, ${ }^{13} \mathrm{XRD}$ peaks of $\mathrm{MnAs}_{1-\mathrm{x}} \mathrm{Si}_{\mathrm{x}} \mathrm{N}_{\delta}(\mathrm{x}=0.03,0.06$, and 0.09) shifts to low angles due to the lattice expansion, which indicates that the nitrogen atoms occupy interstitial sites. With increasing silicon content, the diffraction peaks of both parent alloys and nitrides moves to higher angles which is because small-sized Si atoms occupy the Mn sites. But the shift is less visible than that caused by introduction of nitrogen.

Figure 2 illustrates the position of the interstitial sites in the orthorhombic ${ }^{14}$ and hexagonal structures. The orthorhombic structure is complicated, as indicated in Fig. 2(a). The possible sites that interstitial nitrogen atoms occupy are proposed to be the centers of distorted tetrahedron which consists of two $\mathrm{Mn}$ atoms as the two poles and three As atoms constituting the basal planes. Each orthorhombic cell contains four interstitial sites. However, the hexagonal structure is comparably simple. The possible sites are the center
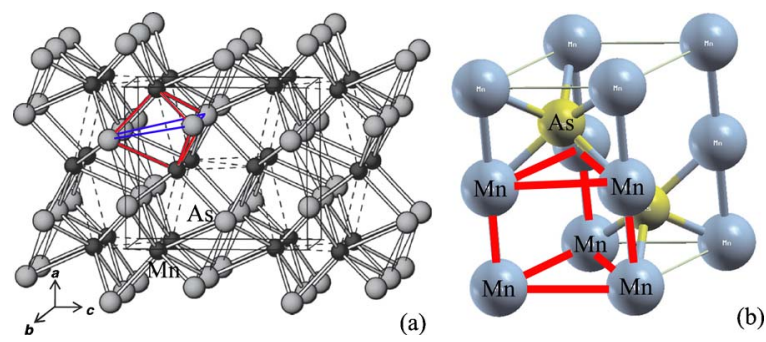

FIG. 2. (Color online) Schematic crystal structures: orthorhombic (a) Ref. 8 and hexagonal (b) structures. In (a) red lines stand for the six edges of distorted pyramid. The blue lines are four edges of basal plane. In (b) the red line consists of the space where the interstitial atoms occupy. 


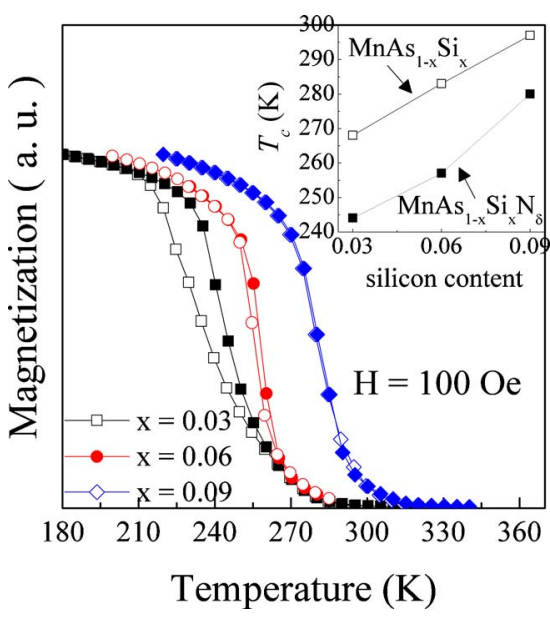

FIG. 3. (Color online) Temperature dependences of magnetization for $\mathrm{MnAs}_{1-\mathrm{x}} \mathrm{Si}_{\mathrm{x}} \mathrm{N}_{\delta}(\mathrm{x}=0.03,0.06$, and 0.09) at $0.01 \mathrm{~T}$. The closed and open symbols represent the heating and cooling processes, respectively. The inset shows the silicon content dependence of Curie temperature of $\mathrm{MnAs}_{1-\mathrm{x}} \mathrm{Si}_{\mathrm{x}} \mathrm{N}_{\delta}$ and $\mathrm{MnAs}_{1-\mathrm{x}} \mathrm{Si}_{\mathrm{x}}(\mathrm{x}=0.03,0.06$, and 0.09). The Curie temperature is determined during heating.

of prism, which is constituted of six Mn atoms. Each hexagonal primary cell contains two largest interstitial sites.

Figure 3 shows the temperature dependence of the magnetization of $\mathrm{MnAs}_{1-\mathrm{x}} \mathrm{Si}_{\mathrm{x}} \mathrm{N}_{\delta}(\mathrm{x}=0.03,0.06$, and 0.09) in a field of $0.01 \mathrm{~T}$. With increasing silicon content, the Curie temperature increases from $245 \mathrm{~K}$ for $\mathrm{MnAs}_{0.97} \mathrm{Si}_{0.03} \mathrm{~N}_{\delta}$ to $280 \mathrm{~K}$ for $\mathrm{MnAs}_{0.91} \mathrm{Si}_{0.09} \mathrm{~N}_{\delta}$. Furthermore, the thermal hysteresis decreases gradually with increasing silicon content and approaches 0 in $\mathrm{MnAs}_{0.91} \mathrm{Si}_{0.09} \mathrm{~N}_{\delta}$ which is beneficial for practical applications. The inset in Fig. 3 compares the Curie temperatures $T_{c}$ of the parent alloys with those of the corresponding nitrides. The Curie temperature of the nitrides is decreased by about $25 \mathrm{~K}$ for each alloy. Curie temperature changes due to interstitial and substitutional modification are widespread in magnetism, as exemplified by $\mathrm{N}$ and $\mathrm{Si}$ in $\mathrm{Sm}_{2} \mathrm{Fe}_{17}$. However, in the present case, it is hard to accurately determine the nitrogen content by mechanical alloying method. So, we just want to evaluate the order of nitrogen content. Gama et al. ${ }^{2}$ had established the relationship between pressure and the Curie temperature in MnAs alloys. Due to the reduction of Curie temperature of ferromagnetic hexagonal about $25 \mathrm{~K}$ by the introduced nitrogen atom, the corresponding lattice pressure change, about $1.2 \mathrm{kbar}$, can be obtained by linear fitting the pressure-Curie temperature relationship. The compressibility of MnAs alloy is estimated to be about $5 \times 10^{-11} / \mathrm{Pa}^{5}$. Therefore volumic change would be around $8 \times 10^{-6}$. Proposed that the abstract lattice volumic change by interstitial atoms should be proportional to the nitrogen ion atomic volume, the interstitial nitrogen content $\delta$ should be the order of $1 \%$. Because the reduction of Curie temperature in nitrides compared with that of those parent alloys is almost same independently with Si content, according to the above discussion, the interstitial nitrogen content would be almost unchanged in each nitride. The ratio of the number of interstitial sites over the number of $\mathrm{Mn}$ atoms in each cell of both two types of structure is 1:1. This means that during the phase transformation, nitrogen content is not

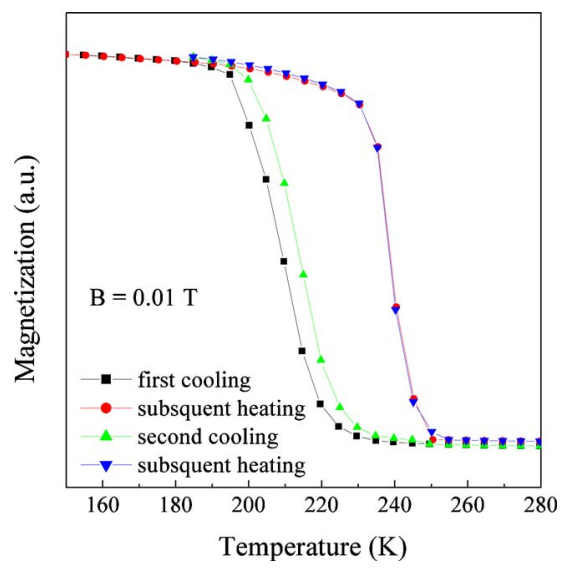

FIG. 4. (Color online) Temperature dependence of the magnetization of as-milled MnAs.

changed. This content is much lower than the nominal content. The extra nitrogen is proposed to form the impurities.

In mechanical-alloyed MnAs, the phase transition temperature in the first cooling process is lower than those measured in subsequently cooling processes (see Fig. 4). By contrast, the phase transition temperature is always same for different heating processes. This phenomenon was named as "virgin effect" and ever reported in the $\mathrm{MnFe}(\mathrm{P}, \mathrm{Si}, \mathrm{Ge})$ system. ${ }^{15}$ However, the origin of virgin effect is still not clear. With increasing $\mathrm{Si}$ content in $\mathrm{Mn}(\mathrm{As}, \mathrm{Si})$ and $\mathrm{Mn}(\mathrm{As}, \mathrm{Si}) \mathrm{N}_{\delta}$, the thermal hysteresis is gradually and the virgin effect disappears in $\mathrm{Mn}(\mathrm{As}, \mathrm{Si})$ and $\mathrm{Mn}(\mathrm{As}, \mathrm{Si}) \mathrm{N}_{\delta}$. So we propose that it is closely related to the first-order phase transition and dependent on strong magnetostructural interactions.

In a martensitic phase transition, the thermal hysteresis reflects the energy barrier during the phase transition. The thermal hysteresis in the first cooling and heating process is larger than that of the others, suggesting that in the first-time cooling process the paramagnetic orthorhombic phase is stable in a wider temperature range. Along with decreasing temperature, the cell volume is decreased from orthorhombic structure [132.7 $\AA^{3}$ (Ref. 16)] to hexagonal structure [129.86 $\AA^{3}$ (Ref. 17)]. Our explanation is that some subgrains at the surface region exert the pressure to the adjacent grains in the inner part of the grains due to the cell contraction during the phase transition. There had been the report that the Curie temperature of MnAs alloy is decreased under pressure. $^{2}$ The cell contraction leads to pressure from outer subgrains onto inner subgrains and lower transition temperature. In the following heating process experiencing the phase transition temperature, due to the structural relaxation and plastically deformation resulted from severe structural phase transition, the stress will be partially released. Therefore, in the subsequent cooling process, the pressure induced by the structural transition is not as severe as that in the first cooling, and a higher phase transition temperature is observed.

To investigate the influence of effect of interstitial nitrogen on the MCE, $M(B)$ magnetization curves of $\mathrm{MnAs}_{1-\mathrm{x}} \mathrm{Si}_{\mathrm{x}} \mathrm{N}_{\delta}(\mathrm{x}=0.03,0.06$, and 0.09) were measured near the Curie temperatures (Fig. 5). The magnetization increases rapidly in low fields and approaches it saturation value, in- 


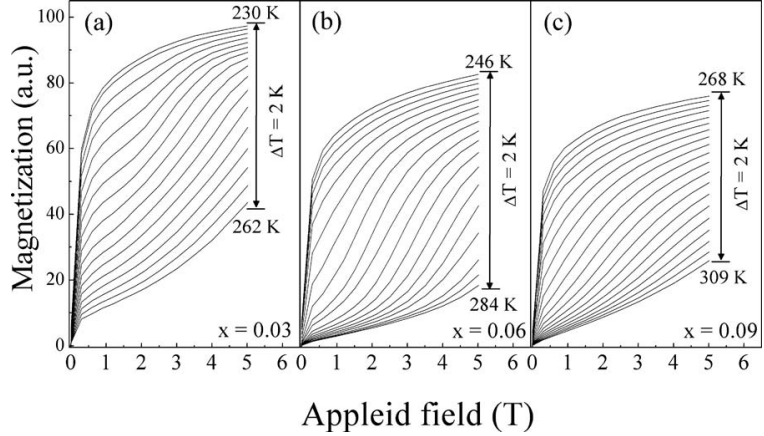

FIG. 5. Isothermal magnetization curves near $T_{c}$ in magnetic fields from 0 to $5 \mathrm{~T}$ for $\mathrm{MnAs}_{1-\mathrm{x}} \mathrm{Si}_{\mathrm{x}} \mathrm{N}_{\delta}$. The Si concentrations $\mathrm{x}$ are 0.03 (a), 0.06 (b), and 0.09 (c). The measurements were carried out during heating.

dicating a stable NiAs-type phase with ferromagnetic order. ${ }^{2}$ With increasing temperature, an inflexion point emerges in the magnetization curves. This indicates a metamagnetic phase transition accompanied by a structural transition from MnP-type paramagnetic orthorhombic structure to NiAs-type ferromagnetic hexagonal one. ${ }^{3}$ However, with increasing silicon content [Fig. 5(c)] the inflexion gradually disappears in contrast to other systems with large thermal hysteresis. ${ }^{2,4,5}$ It is more analogous to a second-order phase transition, related closely with the reduced thermal hysteresis.

The isothermal $\Delta S$ is given by Eq. (2). Figure 6(a) shows the temperature dependences of $\Delta S(T)$ for $\mathrm{MnAs}_{1-\mathrm{x}} \mathrm{Si}_{\mathrm{x}} \mathrm{N}_{\delta}$ $(\mathrm{x}=0.03,0.06$, and 0.09$)$ for a field change of $5 \mathrm{~T}$. A broad peak on the $\Delta S(T)$ curves appears near the respective Curie temperature, unlike the sharp peak typical of in $\mathrm{Fe}$ - or $\mathrm{Cu}$ substituted MnAs, where the phase transition is of the firstorder accompanied by large hysteresis. ${ }^{4,5}$ The entropy change $\Delta S_{\max }$ in $\mathrm{MnAs}_{0.97} \mathrm{Si}_{0.03} \mathrm{~N}_{\delta}$ is $14.6 \mathrm{~J} \mathrm{~kg}^{-1} \mathrm{~K}^{-1}$ at 247 $\mathrm{K}$ for a field change of $5 \mathrm{~T}$, whereas the entropy changes in $\mathrm{MnAs}_{0.94} \mathrm{Si}_{0.06} \mathrm{~N}_{\delta}$ and $\mathrm{MnAs}_{0.91} \mathrm{Si}_{0.09} \mathrm{~N}_{\delta}$ are $12.8 \mathrm{~J} \mathrm{~kg}^{-1} \mathrm{~K}^{-1}$ at $263 \mathrm{~K}$ and $10.6 \mathrm{~J} \mathrm{~kg}^{-1} \mathrm{~K}^{-1}$ at $285 \mathrm{~K}$, respectively, both in field change of $5 \mathrm{~T}$. Although the Curie temperature of nitrides is slightly decreased, the RC is not changed much compared to the parent alloys, as indicated in Fig. 6(b). In $\mathrm{MnAs}_{1-\mathrm{x}} \mathrm{Si}_{\mathrm{x}} \mathrm{N}_{\delta}$ alloys, RC gradually decreases from
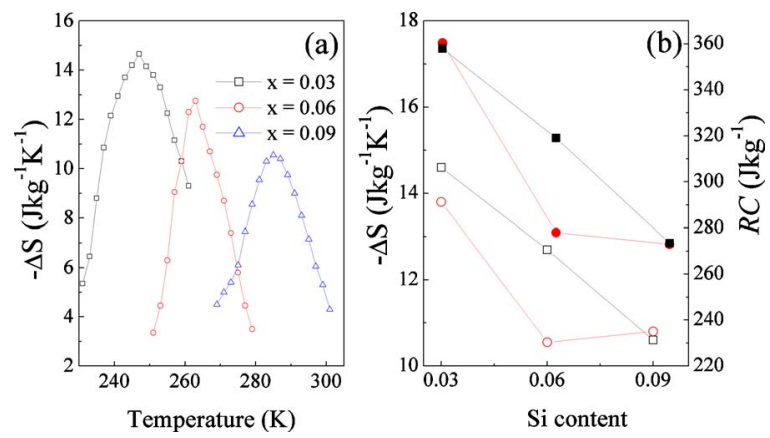

FIG. 6. (Color online) Magnetic entropy change: (a) entropy change as a function of temperature in a magnetic field change of $5 \mathrm{~T}$ for $\mathrm{MnAs}_{1-\mathrm{x}} \mathrm{Si}_{\mathrm{x}} \mathrm{N}_{\delta}$ $(\mathrm{x}=0.03,0.06$, and 0.09); (b) comparison of the maximum values of the magnetic entropy change (open symbols) and RC values (closed symbols) between $\mathrm{MnAs}_{1-\mathrm{x}} \mathrm{Si}_{\mathrm{x}} \mathrm{N}_{\delta}(\mathrm{x}=0.03,0.06$, and 0.09) (dark symbols) and their parent (red symbols) alloys. The entropy data of the parent alloys are taken from Ref. 13.
$360 \mathrm{~J} \mathrm{~kg}^{-1}$ in $\mathrm{MnAs}_{0.97} \mathrm{Si}_{0.03} \mathrm{~N}_{\delta}$ to $319 \mathrm{~J} \mathrm{~kg}^{-1}$ in $\mathrm{MnAs}_{0.94} \mathrm{Si}_{0.06} \mathrm{~N}_{\delta}$ and $274 \mathrm{~J} \mathrm{~kg}^{-1}$ in $\mathrm{MnAs}_{0.91} \mathrm{Si}_{0.09} \mathrm{~N}_{\delta}$. Due to their $T_{\mathrm{c}}$ around room temperature and large $\mathrm{MCE}$ and $\mathrm{RC}$, $\mathrm{MnAs}_{1-\mathrm{x}} \mathrm{Si}_{\mathrm{x}} \mathrm{N}_{\delta}(\mathrm{x}=0.03,0.06$, and 0.09) compounds are potential candidates for ambient magnetic refrigeration.

\section{CONCLUSIONS}

In summary, we have investigated how interstitial nitrogen and substitutional silicon affect the magnetocaloric properties of MnAs. Thermal and magnetic hystereses are both reduced to nearly zero as the silicon content in $\mathrm{MnAs}_{1-\mathrm{x}} \mathrm{Si}_{\mathrm{X}} \mathrm{N}_{\delta}$ decreases. Compared to the parent alloys, the Curie temperature is reduced by interstitial nitrogen. The maximum magnetic entropies higher than $10 \mathrm{~J} \mathrm{~kg}^{-1} \mathrm{~K}^{-1}$ are also obtained in $\mathrm{MnAs}_{1-\mathrm{x}} \mathrm{Si}_{\mathrm{x}} \mathrm{N}_{\delta}$ alloy. The nitrides exhibit a virgin effect in MnAs which is similar to the virgin effect in $\mathrm{MnFe}(\mathrm{P}, \mathrm{Si}, \mathrm{Ge})$ system. The Curie temperature of $\mathrm{MnAs}_{1-\mathrm{x}} \mathrm{Si}_{\mathrm{x}} \mathrm{N}_{\delta}$ alloy near room temperature, the large $\Delta S_{\max }$, and the low thermal and magnetic hysteresis losses suggest that $\mathrm{MnAs}_{1-\mathrm{x}} \mathrm{Si}_{\mathrm{x}} \mathrm{N}_{\delta}(\mathrm{x}=0.03,0.06$, and 0.09) may be developed into a room temperature refrigeration material.

\section{ACKNOWLEDGMENTS}

This work has been supported by the National Nature Science Foundation of China under Grant Nos. 50831006 and 50971123 and National Basic Research Program (Grant No. 2010CB934603) of China, the Ministry of Science and Technology of China. Research at Nebraska was supported by the U.S. DOE BES Program (Grant No. DE-F60204ER46152) and NRI.

${ }^{1}$ H. Wada and Y. Tanabe, Appl. Phys. Lett. 79, 3302 (2001).

${ }^{2}$ S. Gama, A. A. Coelho, A. de Compos, A. M. G. Carvalho, F. C. G. Gandra, P. J. von Ranke, and N. A. de Oliveria, Phys. Rev. Lett. 93, 237202 (2004).

${ }^{3}$ J. Mira, F. Rivadulla, J. Rivas, A. Fondado, T. Guidi, R. Caciuffo, F. Carsughi, P. G. Radaelli, and J. B. Goodenough, Phys. Rev. Lett. 90, 097203 (2003).

${ }^{4}$ D. L. Rocco, A. de Campos, A. M. G. Carvalho, L. Caron, A. A. Coelho, S. Gama, F. C. G. Gandra, A. O. dos Santos, L. P. Cardoso, P. J. von Ranke, and N. A. de Oliveira, Appl. Phys. Lett. 90, 242507 (2007).

${ }^{5}$ A. de Campos, D. L. Rocco, A. M. G. Carvalho, L. Caron, A. A. Coelho, S. Gama, L. da Silva, F. C. G. Gandra, A. O. dos Santos, L. P. Cardoso, P. J. von Ranke, and N. A. de Oliveira, Nature Mater. 5, 802 (2006).

${ }^{6}$ K. Mandal, D. Pal, O. Gutfleisch, P. Kerschl, and K. H. Müller, J. Appl. Phys. 102, 053906 (2007).

${ }^{7}$ Y. F. Chen, F. Wang, B.-G. Shen, G. J. Wang, and J.-R. Sun, J. Appl. Phys. 93, 1323 (2003).

${ }^{8}$ A. Giguère, M. Foldeaki, B. Ravi Gopal, R. Chahine, T. K. Bose, A. Frydman, and J. A. Barclay, Phys. Rev. Lett. 83, 2262 (1999).

${ }^{9}$ K. A. Gschneidner, Jr., V. K. Pecharsky, E. Brück, H. G. M. Duijn, and E. M. Levin, Phys. Rev. Lett. 85, 4190 (2000).

${ }^{10}$ G. J. Liu, J. R. Sun, J. Shen, B. Gao, H. W. Zhang, F. X. Hu, and B. G. Shen, Appl. Phys. Lett. 90, 032507 (2007).

${ }^{11}$ K. A. Gschneidner, Jr., V. K. Pecharsky, A. O. Pecharsky, and C. B. Zimm, Mater. Sci. Forum 315-317, 69 (1999).

${ }^{12}$ M. E. Wood and W. H. Potter, Cryogenics 25, 667 (1985).

${ }^{13}$ W. B. Cui, W. Liu, X. H. Liu, S. Guo, Z. Han, X. G. Zhao, and Z. D. Zhang, J. Alloys Compd. 479, 189 (2009).

${ }^{14}$ A. P. Grosvenor, R. G. Cavell, and A. Mar, J. Solid State Chem. 181, 2549 (2008).

${ }^{15}$ D. T. C. Thanh, E. Brück, O. Tegus, J. C. P. Klaasse, T. J. Gortenmulder, and K. H. J. Buschow, J. Appl. Phys. 99, 08Q107 (2006).

${ }^{16}$ JCPDS Card No. 76-0009.

${ }^{17}$ JCPDS Card No. 89-5150. 